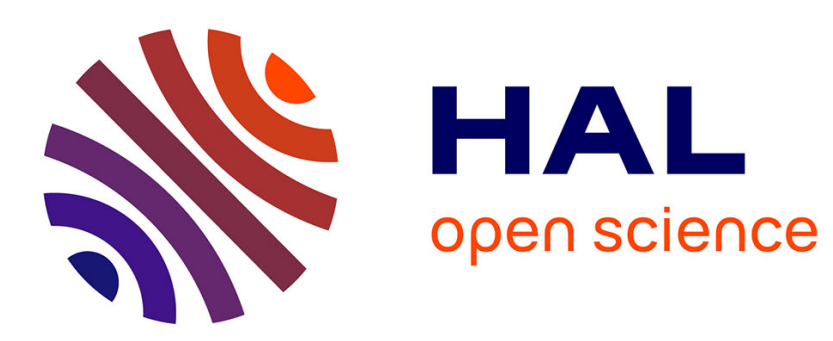

\title{
Does song repertoire size in Common Blackbirds play a role in an intra-sexual context?
}

Nana Hesler, Roger Mundry, Torben Dabelsteen

\section{To cite this version:}

Nana Hesler, Roger Mundry, Torben Dabelsteen. Does song repertoire size in Common Blackbirds play a role in an intra-sexual context?. Journal für Ornithologie = Journal of Ornithology, 2010, 152 (3), pp.591-601. 10.1007/s10336-010-0618-5 . hal-00647967

\section{HAL Id: hal-00647967 https://hal.science/hal-00647967}

Submitted on 4 Dec 2011

HAL is a multi-disciplinary open access archive for the deposit and dissemination of scientific research documents, whether they are published or not. The documents may come from teaching and research institutions in France or abroad, or from public or private research centers.
L'archive ouverte pluridisciplinaire HAL, est destinée au dépôt et à la diffusion de documents scientifiques de niveau recherche, publiés ou non, émanant des établissements d'enseignement et de recherche français ou étrangers, des laboratoires publics ou privés. 
1 Does song repertoire size in common blackbirds play a role in an intra-sexual context?

3 Nana Hesler $^{1}$, Roger Mundry ${ }^{2}$, Torben Dabelsteen ${ }^{1}$

4

$5 \quad{ }^{1}$ University of Copenhagen, Universitetsparken 15, 2100 Copenhagen, Denmark

$6 \quad{ }^{2}$ Max Planck Institute for Evolutionary Anthropology, Deutscher Platz 6, 04103 Leipzig,

7 Germany

9 Abstract

10 Bird song is thought to have a function in both inter- and intra-sexual contexts with song

11 complexity serving as an honest signal of male quality. Theory predicts that males use

12 repertoire sizes to estimate rivals' fighting ability. Here we tested whether element

13 repertoire size plays a role in an intra-sexual context in the common blackbird Turdus

14 merula, a songbird with a large repertoire. In a territory intrusion playback experiment

15 we broadcast common blackbird song with different element repertoire sizes to territorial

16 males. The test birds did not respond differently to the different repertoire sizes. This was

17 also the case when we considered the test birds' own repertoire sizes in the analysis.

18 Thus, we found no evidence for the hypothesis that males use repertoire size for

19 estimating rivals' fighting force. However, this does not exclude the possibility that

20 repertoire size plays a role in different intra-sexual contexts in common blackbirds. In the

21 discussion, we address alternative scenarios. 


\section{Zusammenfassung}

\section{Spielt die Größe des Gesangsrepertoires bei Amseln eine Rolle in einem intra-}

26 sexuellen Kontext?

27 Vogelgesang spielt sowohl in inter- als auch intra-sexuellen Kontexten eine Rolle, wobei

28 angenommen wird, dass die Gesangskomplexität die Qualität des singenden Männchens

29 anzeigt. Männchen könnten die Konkurrenzstärke von Rivalen an der Größe ihres

30 Gesangsrepertoires abschätzen. Wir testeten hier an der Amsel Turdus merula, einem

31 Singvogel mit einem großen Repertoire, ob die Größe des Elementrepertoires eine Rolle

32 in einem intra-sexuellen Kontext spielt. In einem Playback-Experiment mit territorialen

33 Männchen spielten wir Amselgesang mit verschiedenen Elementrepertoiregrößen ab. Die

34 Testvögel reagierten nicht unterschiedlich auf die verschiedenen Repertoiregrößen, was

35 auch dann der Fall war, wenn wir die Repertoiregröße der Testtiere selber

36 berücksichtigten. Folglich fanden wir keine Bestätigung der Hypothese, dass Männchen

37 gesangliche Repertoiregrößen benutzen, um die Konkurrenzstärke von Rivalen

38 einzuschätzen. Dies schließt jedoch nicht die Möglichkeit aus, dass Repertoiregrößen bei

39 Amseln in anderen intra-sexuellen Kontexten eine Rolle spielen. Wir diskutieren deshalb

40 verschiedene alternative Szenarien. 


\section{Introduction}

44 In most oscine bird species, male song is composed of different song types and/or song

45 elements. These repertoires are generally seen as the outcome of sexual selection driven

46 by female choice and male-male competition, with repertoire size serving as a signal of

47 male quality (review e.g. in Collins 2004, Catchpole \& Slater 2008). Even though this

48 hypothesis is widely accepted and supported by several studies, the meaning of repertoire

49 sizes in different contexts remains unclear.

50 In classic speaker replacement experiments, territorial males were removed and

51 speakers playing back conspecific song were installed in their territories. In both great tits

52 (Parus major, Krebs et al. 1978) and red-winged blackbirds (Agelaius phoeniceus,

53 Yasukawa, 1981), playback containing a repertoire of different song types was more

54 efficient in keeping out intruders than playback comprised of a single song type.

55 However, a common problem of these studies is the fact that the single song type

56 playbacks contained single songs from one individual while the repertoire playbacks

57 consisted of several song types from several different individuals. Assuming that

58 individuality may be encoded in song (Weary \& Krebs 1992, but see also Gentner et al.

59 2000) and can be decoded by a receiver, the test birds of these experiments may have

60 perceived the repertoire playback as song originating from multiple birds rather than one

61 bird with a large repertoire. As a quality signal, repertoire size could be used by males to

62 estimate other males' fighting ability in actual encounters. Only a few studies have tested

63 the direct response to different repertoire sizes, leading to ambiguous results. In a two

64 speaker experiment, male territorial field sparrows Spizella pusilla approached closer to

65 the speaker playing larger repertoires (Searcy 1983), and male song sparrows Melospiza 
66 melodia reacted more persistently to playback of larger repertoires (Stoddard et al. 1988).

67 However, in other experiments - even one conducted with song sparrows - the reaction

68 of male birds did not vary in accordance with different repertoire sizes (song sparrow,

69 Searcy 1983; sedge warbler Acrocephalus schoenobaenus, Catchpole 1989). In species

70 with discontinuous song (i.e. song which is structured into discrete songs and pauses),

71 repertoire size is usually measured as the number of different song types (a song type

72 always contains the same element types, which are the shortest song unit). In the

73 chaffinch Fringilla coelebs, a species with a small song type repertoire, within-song

74 complexity is meaningful to both females and males (Leitão et al. 2006). Also, Balsby \&

75 Dabelsteen (2001) found that male whitethroats Sylvia communis did not respond to

76 differences in repertoire size, but song length, and suggested that in this species the

77 evolution of repertoire size is not driven by male competition.

78 These inconsistent results may have several reasons. First, a territory owner's

79 response towards an intruder may not only depend on the intruder's fighting ability, but

80 also on the territory owner's fighting ability relative to that of the intruder (Searcy \&

81 Beecher 2009). Therefore a bird with a small repertoire may react highly aggressively

82 towards a small repertoire intruder, but choose a different strategy when a large repertoire

83 male is intruding, who would probably be a superior rival in a fight. A solution to this

84 problem is to take the test birds' own repertoire sizes into consideration when evaluating

85 their response to playbacks of different repertoire sizes, as was by done Balsby \&

86 Dabelsteen (2001). Second, different songbird species may use a diversity of singing

87 styles, ranging from continuous to discontinuous singing, with repertoire sizes at different

88 levels of song organisation (song vs. element). To date, most studies on song complexity 
89 concern species with either small song type repertoires or no song types at all [for

90 example: sedge warbler 30-55 syllables, great reed warbler Acrocephalus arundinaceus

91 10-20 syllables (Catchpole 1980); great tit 2-5 song types, red-winged blackbird 2-6 song

92 types, song sparrow 5-11 song types (Beecher et al. 2000); but also common nightingale

93 Luscinia megarhynchos 150-230 song types (Kipper et al. 2004)]. However, it is possible

94 that a more clear effect of repertoire size can be seen in species with large repertoires.

95 Therefore, we chose to investigate the common blackbird Turdus merula (from

96 now on called 'blackbird'), which has a large repertoire and a complex singing style

97 without fixed song types. Full song is organised into single songs (Strophen) of about 2

98 sec, separated by silent intervals of ca. 3 sec. A typical blackbird's full song starts with a

99 long-ranging whistle part consisting of 3-5 low-frequency elements $(1.5-3 \mathrm{kHz})$ and ends

100 with a twitter part comprising a more variable number of elements with a broader

101 frequency range and on average higher frequency $(2-\mathrm{ca} .10 \mathrm{kHz})$ and a considerably lower

102 sound pressure level (SPL; Todt 1981; Dabelsteen 1984; Fig. 1). Entire songs are only

103 occasionally repeated, but there are 'motifs', that is, fixed sequences of elements, which

104 are always sung in the same order (Dabelsteen 1984, 2005; Rasmussen \& Dabelsteen

105 2002). These motifs are combined in a flexible way within songs, and the fact that they

106 repeatedly occur in different songs of a male gives them some resemblance with the song

107 types of other species. Thus, in terms of song organisation, blackbirds are between a

108 discontinuous singing style with song type repertoires and a continuous singing style

109 without any song types. Previous studies have shown that there are large inter-individual

110 differences in motif repertoire size and that song is used in both intra- and inter-sexual

111 contexts (Rasmussen \& Dabelsteen 2002). Furthermore, in another study we found 
112 correlations between body size and repertoire size in the blackbird, indicating that

113 repertoire size is a potential signal of male quality in this species (Hesler 2010).

114 In this study we investigate the importance of repertoire sizes in the blackbird in

115 an intra-sexual context. In a playback experiment, we broadcast song with different

116 element repertoire sizes (small versus large) to territorial males, and compared their

117 responses, taking the test birds' own repertoire sizes into account. If males use repertoire

118 size to estimate a rival's fighting ability, we expect test subjects to react differently to the

119 different repertoire sizes, presumably with the strength of reaction increasing as the

120 repertoire size broadcast increases. Furthermore, we predicted that the response may

121 depend on the bird's own repertoire size, i.e. its own quality (Balsby \& Dabelsteen 2001,

122 Searcy \& Beecher 2009). For example, a bird with a large repertoire size might react

123 more strongly to playback of large repertoires, because they expect a stronger opponent.

124 On the other hand, birds with small repertoires may react less strongly to playback of

125 large repertoires, as they would expect an opponent who is stronger than themselves.

127 Methods

128 Study population

129 The study was conducted on the island of Helgoland, Germany. The blackbird population

130 there consists of ca. 80 breeding pairs, most of whom breed in the residential areas of the

131 island and are thus very well habituated to humans. Most of the population was colour-

132 ringed with permission given by the Vogelwarte Helgoland (Sacher et al. 2006).

134 Song recordings and repertoire analyses 
135 All recordings used were taken from colour-ringed males during dawn chorus ca. $1 \mathrm{hr}$

136 before sunrise (03:40 - 06:30) in the early breeding seasons (8. April - 10. June) of 2006

137 -2008. All recorded males were in their third calendar year or older. These birds were

138 distinguishable from second-calendar year males by a moult border in the greater coverts

139 (Svensson 1992).

140 We used a directional microphone (Sennheiser K6/ME67) and a Marantz PMD

141670 solid state recorder with a sample rate of $22050 \mathrm{~Hz}$ (2006) or $44100 \mathrm{~Hz}(2007,2008)$

142 to record songs. Recordings in $44100 \mathrm{~Hz}$ were resampled to $22050 \mathrm{~Hz}$. Avisoft-SASLab

143 Pro $4.4-4.52$ was used for all sound analyses. Recordings were filtered (butterworth,

144 high pass $1.5 \mathrm{kHz}$, low pass $10 \mathrm{kHz}$ ) and cut into single songs. Printed spectrograms were

145 used for repertoire analyses (settings: FFT 512, window Hamming, bandwith $56 \mathrm{~Hz}$,

146 resolution $43 \mathrm{~Hz}$, frame size 100\%, overlap 75\%, resolution $5.8 \mathrm{~ms}$; graphical scale on

147 prints: $1 \mathrm{sec}=36 \mathrm{~mm}, 1 \mathrm{kHz}=6 \mathrm{~mm}$ ). All repertoire analyses were carried out by the

148 same person by visual inspection of the spectrograms (N.H.). We classified all elements

149 in the recordings according to their overall appearance on the spectrogram (frequency and

150 temporal characteristics). An element was defined as a single continuous trace in time

151 without visible sound free pauses, i.e. pauses longer than ca. $0.015 \mathrm{sec}$ (Fig. 1). Intra-

152 individual pause durations between two element types can be highly variable. If elements

153 appeared at least once with a distinguishable pause, they were always considered as two

154 elements, even if they sometimes appeared as one continuous element. Repertoire sizes

155 were determined by counting the number of different elements in 100 consecutive songs,

156 including both whistle and twitter elements. We reasoned that it should be possible to 
157 adequately assess inter-individual differences on the basis of 100 songs, even if this does

158 not always reflect a blackbird's full repertoire (Fig. 2).

160 Construction of test files for playback

161 We constructed sound files for playback with large and small element repertoire sizes. In

162 order to avoid confounding influence by song parameters other than that we were

163 interested in (repertoire size), we did not use song from birds with naturally small and

164 large repertoires. Instead, we created large and small repertoires using recordings from

165 the same bird. It is possible that identity of the singer is encoded in voice characteristics

166 in the song and can be identified by a listening bird (Weary \& Krebs 1992), which could

167 influence the response to the playback. Therefore we decided to use playbacks from two

168 different stimulus birds for each test bird. We ran the experiment with 16 test birds using

169 recordings from 8 stimulus birds which meant that the songs from each stimulus bird

170 were used four times (twice as small and twice as large repertoire playback). For

171 instance, test birds 1 and 9 would receive playback of a large repertoire from stimulus

172 bird A and small repertoire from stimulus bird B whereas test birds 2 and 10 would

173 receive large repertoire from bird B and small from bird A and so on. In order to control

174 for pseudoreplication we included the stimulus ID in the statistical analysis (see below).

175 To create a large repertoire for playback, we first analysed a recording of $\geq 100$

176 songs from a stimulus bird and then selected a sequence of 50 songs with the largest

177 possible element repertoire. This was achieved by deleting songs from the sequence

178 which contained only or mostly element types also present in other songs. The repertoire

179 size in the derived sequence determined the repertoire size of the corresponding small 
180 repertoire size to be broadcast (ca. half the large repertoire size). Then we constructed the

181 playback sequence with the small repertoire, using the same procedure as above, except

182 that this time songs were chosen such that they added the smallest available amount of

183 new elements types to the sequence. These procedures resulted in large repertoire

184 playbacks with repertoires slightly higher than in the original recording and small

185 repertoire playbacks with repertoires considerably smaller. On average, the large

186 repertoires had 237 different element types (range 190-276), and small repertoires 120

187 element types (range 85-152). Playback files were matched in such a way that the large

188 repertoire was ca. twice as large as the small one. Recordings from birds with an

189 originally small repertoire size were not used, since we would then create unnaturally

190 small repertoires.

191 Since the natural order of songs was jumbled to a higher degree in the small than

192 large playback files, we randomized the order of songs in both the large and small

193 repertoire playback files. We however avoided direct repetitions of songs, as this occurs

194 rarely in natural song. The 50 songs of a file were played back with a delivery cadence of

$1955 \mathrm{sec}$, resulting in a total duration of $250 \mathrm{sec}$. The maximum volume of each song (peak

196 amplitude) was normalized to $90 \%$ of the maximal possible amplitude of the system, and

197 the pauses between songs were filled with background noise from the same recordings.

198 We matched the two recordings used for the same test bird in song duration and

199 twitter part duration since these characteristics may influence response strength

200 (Dabelsteen \& Pedersen 1990; Balsby \& Dabelsteen 2001). Also after manipulation,

201 songs in the large and small repertoire playback did not differ systematically in song

202 length (mean of means \pm sd; large playback repertoire: $2.69 \sec \pm 0.28$, small playback 
203 repertoire: $2.66 \mathrm{sec} \pm 0.48$; Wilcoxon's matched pairs signed ranks test of the average

204 song durations in the large vs. small repertoire files from the same stimulus bird: $\mathrm{T}^{+}=18$,

$205 \mathrm{~N}=8, \mathrm{P}=1$; and of average song durations of the two files which were played to the

206 same test subject: $\left.\mathrm{T}^{+}=18, \mathrm{~N}=8, \mathrm{P}=1\right)$. The number of different element types per song

207 and the ratio between whistle and twitter element types did not differ significantly after

208 manipulation either (comparing songs in the small and large repertoire files from the

209 same stimulus bird; number of element types: $\mathrm{T}^{+}=30, \mathrm{~N}=8, \mathrm{P}=0.11$; ratio of whistle to

210 twitter element types: $\mathrm{T}^{+}=25, \mathrm{~N}=8, \mathrm{P}=0.38$ ).

211

212 Playback procedure

213 We conducted the playback experiments in spring 2008 (6. April - 6. May, after

214 dawn chorus and before noon) with 16 territorial males who were colour-ringed and at

215 least in their 3. calendar year. Most were paired with a female which was in the nest

216 building phase and very likely in her fertile phase. We chose this critical stage of the

217 breeding cycle, because we obtained very weak reactions during pilot experiments earlier

218 in the season in 2007 in the same population. Each test bird was tested twice (small and

219 large repertoire playback tests), on consecutive days (except for one bird that was tested

220 with three days between tests). The order of treatments was balanced. We played only

221 recordings from birds that had their territories in a different area of the island than the test

222 bird throughout their lifetime. On the same day, we did not test birds in earshot of each

223 other; neither did we use playbacks from same stimuli birds for test subjects in earshot of

224 each other. The test files were played back using a CD player (Sony CD D-NE330) and a

225 Nagra DSM speaker. The output level was calibrated to maximum values of ca. $65 \mathrm{~dB}(\mathrm{~A})$ 
226 at 10 m (Brühl \& Kjær 2206, fast setting), which is the natural level of blackbird full

227 song (Dabelsteen 1981). We placed the speaker in the test subject's territory. Due to the

228 often very small and adjacent territories on Helgoland, neighbouring males often

229 interfered during the experiments; therefore we placed the speaker centrally in the

230 territory, i.e. between ca. 10-20 m from the territory border (as most territories were in

231 the residential areas of the island we were somewhat restricted in positioning the

232 speakers). The speaker was placed at the same position for both experiments, put on a

233 suitable object in a height between ca. 20 and $150 \mathrm{~cm}$. Most birds on the island are very

234 well habituated to humans and used to human activity in their territories, so test birds

235 rarely seemed disturbed when we set up the speaker. However, we waited at least 3 min

236 before starting the experiments. We started playback while the test bird was in sight.

237 We recorded the following behaviours during the $250 \mathrm{sec}$ of the playback and 120

238 sec afterwards: Flight, bow posture (neck stretched forward, beak pointing downwards,

239 rump feathers typically fluffed, tail fanned), tail up posture (tail going upwards and down

240 again in a fast movement), and distance to speaker (on speaker, $0 \mathrm{~m}$ to $<1 \mathrm{~m}, 1 \mathrm{~m}$ to $<5$

$241 \mathrm{~m}, 5 \mathrm{~m}$ to $<10 \mathrm{~m}, 10 \mathrm{~m}$ or more; for a more detailed description of the postures, see

242 Dabelsteen 1982, Dabelsteen \& Pedersen 1985).

243 Song and other vocalisations were also recorded, but occurred too rarely to

244 provide data for analysis. Only twitter song was elicited frequently by playback. This is a

245 different singing style which resembles the twitter part in full song and is used in

246 aggressive interactions (Dabelsteen et al. 1998, Klump et al. 2010). However, due to the

247 low amplitude of this vocalisation and the relatively high background noise level during

248 experiments it was not possible to quantify it reliably. When a test bird was interacting 
249 with another bird, we continued the playback but did not use behaviours during this

250 interaction as data. (5 test subjects had interactions with females, one subject had an

251 interaction with a male). We attempted to increase the sample size by testing 6 further

252 males, but these data could not be used due to frequent interruption by neighbouring

253 males.

254 We were able to record full song from 15 of the 16 test subjects. We made the 255 recordings during dawn chorus in the same breeding season. They had repertoire sizes of

$256257 \pm 70$ (mean \pm SD) element types with a large range (116-395 element types) in the

257 first 100 songs (Fig. 2). We did not know the subjects' repertoire sizes prior to the

258 experiments. Retrospective comparison of these with the playback repertoire sizes

259 showed that in sequences of 50 songs, the repertoire size of 10 test subjects was between

260 the sizes of the small and the large repertoire broadcast, 4 had repertoires larger than the

261 large playback and only one had a repertoire that was smaller than the small playback

262 with which the respective bird was tested.

264 Statistical analyses

265 We analysed data separately for the period during the playback and the two minutes

266 afterwards. During playback we used ten response variables: Rates $(\mathrm{n} / \mathrm{sec})$ of the

267 behaviours flight, tail up, bow, latency and mean timing (sec) of the behaviours flight and

268 tail up. 'Mean timing' reflects the timing of the behaviours. It was calculated as the mean

269 of all times of occurrence of the respective behaviour (in seconds after start of playback)

270 during the observed period. We used three distance measurements: mean and minimum

271 distance to the speaker (m) and distance slope, which is the slope of a regression between 
272 distance and time. The latter was used in order to estimate the spatial behaviour relative

273 to time (i.e., whether the bird was approaching or moving away from the speaker over

274 time). For the period after playback we used only the rates of the behaviours flight and

275 tail up as well as the same distance measurements as before. Low latencies, high rates

276 with long occurrences and short distances indicate a strong response during and after

277 playback (e.g. Dabelsteen 1982).

278 To consolidate the response variables, we conducted two Principal Component

279 Analyses (PCA), one for response variables obtained during and one for those obtained

280 after the playback. Since distance slope was only weakly correlated to the other variables

281 (largest absolute correlation: during playback 0.299, after 0.236) we excluded it from the

282 PCAs. Large correlations between some of the variables, the Kaiser-Meyer-Olkin

283 measure of sampling adequacy, as well as Bartlett's test of sphericity (McGregor 1992)

284 indicated that both PCAs were justified (Table 1). We used Varimax-Rotation in order to

285 achieve easy interpretable factors. The PCAs extracted three principal components with

286 an Eigenvalue $>1$ for the variables collected during and two for the variables collected

287 after playback (Table 1). In the following analyses we used factor scores derived from the

288 PCAs as well as distance slopes as response variables.

289 We tested the influence of the playback on the subjects' behaviours using

290 Generalized Linear Mixed Models (GLMM; Baayen 2008a). We included as fixed effects

291 1) stimulus repertoire size, 2) stimulus order, 3) experiment number (first or second

292 experiment), 4) the mean duration of the respective playback songs. We also included the

293 test subject's own repertoire size and its interaction with the stimulus repertoire size as an

294 additional fixed effect. Since the repertoire size of one of the 16 test subjects was 
295 unknown, we ran the model once including this effect and once excluding it (but

296 achieving a larger sample size). As random effects we initially included the ID of the

297 tested individual and the individual from which the broadcast songs were recorded.

298 However, we removed the latter since it appeared to be insignificant (all likelihood ratio

299 tests except for one $\mathrm{P}>0.5$, one $\mathrm{P}=0.20$ ).

300 We ran the GLMM once for each of the seven response variables (during

301 playback: PC1, PC2, PC3, distance slope; after playback: PC1, PC2, distance slope).

302 Since some individuals left immediately after the playback ended, the sample size for the

303 period after was smaller. Thus, we used four different combinations of experimental

304 periods and fixed effects (during playback: 32/30 experiments; after playback: 29/27

305 experiments excluding/including the subject's repertoire size) and ran the model

306 altogether $4 \times 7$ times.

307 Several of the fixed effects were considered to be 'control variables' (i.e. stimulus

308 order, experiment number, mean duration of the respective playback songs). We were not

309 interested in their statistical significance per se but simply wanted to control for potential

310 effects of these variables. If these were non-significant $(\mathrm{P}>0.25)$, we removed them

311 from the model prior to testing for the effects of the subject's own repertoire size and its

312 interaction with the stimulus repertoire size.

313 We tested for the significance of the random effects using likelihood ratio tests

314 (Dobson 2002; Bolker et al. 2009) based on models fit using Maximum Likelihood

315 (rather than restricted Maximum Likelihood). To test the significance of fixed effects we

316 used Monte-Carlo Markov-Chain (MCMC) analysis (Baayen 2008a, Bolker et al. 2009).

317 We checked for homogeneous variance and approximate normal distribution of residuals 
318 by visually inspecting residuals plotted against predicted values. We also checked for

319 interrelations between predictor variables using Variance Inflation Factors (VIF). We

320 also calculated VIFs for dummy coded stimulus number (Field 2005). The largest VIF

321 was 1.1, ruling out collinearity issues. To achieve reliable tests of their interaction, we z-

322 transformed repertoire size of the test subjects and playback, respectively, to a mean of

323 zero and a standard deviation of one (Aiken \& West 1992).

324 PCAs were calculated using SPSS 15.0.0 for Windows. We calculated GLMMs

325 using the function 'Imer' provided by the package 'Ime4' (version 0.999375-31; Bates et

326 al. 2008) for R (version 2.9.1; R Development Core Team 2008). We derived MCMC P-

327 values using the function 'pvals.fnc' from the R-package 'languageR' (version 0.953,

328 Baayen 2008b). Variance inflation factors were run using scripts written for R by R. M.

330 Results

331 When we started playback, most of the test subjects reacted immediately by stopping

332 their current behaviour and/or starting to fly around. In most cases they reacted strongly

333 and aggressively, flying low over the speaker and/or landing on it while uttering

334 continuous twitter song. During playback, test birds performed $3.13 \pm 1.68$ (mean $\pm \mathrm{sd}$ )

335 tail up postures per minute, $2.23 \pm 1.26$ flights per minute and $1.75 \pm 2.56$ bow postures

336 per minute with a latency of $25 \pm 22.45 \mathrm{sec}$ until the first occurrence of tail up posture

337 and a latency of $32 \pm 52.28 \mathrm{sec}$ until the first flight.

338 The repertoire size of the playback files had no significant influence on the test

339 birds' responses, nor was there an interaction between the test birds' and playback

340 repertoire sizes. Also, none of our 'control variables' (the mean duration of the respective 
341 playback songs, stimulus order, number of experiment, or the identity of the stimulus bird

342 and the test subject itself) had a recognizable effect on any of the responses. This was the

343 case both when we did not take the subjects' own repertoire sizes into consideration

344 (Table 2) and when we did (Table 3).

346 Discussion

347 In our playback experiment blackbirds did not respond differently towards playbacks of

348 different repertoire sizes. This was also the case when we took the test birds' own

349 repertoire sizes into account. Thus, with our experiment we found no evidence supporting

350 the hypothesis that male blackbirds use other males' repertoire sizes to estimate a rival's

351 quality. Considering the body of literature implying that both inter- and intra-sexual

352 selection are driving forces in the evolution of repertoires (for an overview, see Collins

353 2004), this seems to be a surprising result (but see Catchpole 1989).

$354 \quad$ In many other studies very similar methods have been used in playback

355 experiments with songbirds and even blackbirds (e.g. Dabelsteen 1982; Dabelsteen \&

356 Pedersen 1985, 1990; Stoddard 1988; Balsby \& Dabelsteen 2001; Briefer et al. 2008) and

357 our test subjects showed strong responses to our playbacks. The rates of the recorded

358 behavioural patterns were comparable to those observed by Dabelsteen (1982) in a

359 playback experiment with blackbirds. We therefore think that the general design which

360 we used should be suitable to detect differences in response if there were any.

361 A crucial question is whether the test birds were able to assess the differences in

362 repertoire sizes in our experiments at all. We presented the stimuli over a relatively short

363 time and the repertoire sizes in the 50 songs of our playback were much smaller than a 
364 normal full repertoire of a blackbird, in which new element types can occur even after

365300 consecutive songs (unpubl. data). However, differences in repertoire sizes of the two

366 stimuli were very clear and if it is indeed necessary to hear the full repertoire of a rival in

367 order to assess his quality, it would not be feasible to use repertoire sizes for quality

368 assessment in short encounters. In our experiments, the test birds had to hear at least ca.

$369100 \mathrm{sec}$ of playback (corresponding to ca. 20 songs) in order to have the opportunity to

370 detect differences in repertoire sizes. In most cases the test birds started responding

371 earlier, meaning that their first response cannot have been based on the repertoire size

372 broadcast. However, during the rest of the playback and in the period afterwards they

373 could have adjusted their response if the perceived threat was dependent on repertoire

374 size, as described by Stoddard et al. (1988) for song sparrows. Nevertheless, even if the

375 test birds were able to distinguish between the two repertoire sizes, the magnitude of

376 response was similar during the broadcasting of both repertoire sizes.

377 This finding may be due to a ceiling effect. In our experiment, the test birds were

378 confronted with the simulation of an unknown intruder singing full song from within

379 their territory - usually during a period in which the subjects' females were likely to be

380 fertile (before/during the egg laying period). The strong immediate responses indicate

381 that the test birds perceived the playback as a strong threat. We chose this design as we

382 experienced very weak reactions in pilot experiments, which were carried out in 2007 but

383 later in the season and thus in a less critical stage of the breeding cycle. To the territory

384 holder, such an intrusion may represent the risk of loosing parts of his territory or his

385 female engaging in extra-pair copulations with the unknown intruder. Furthermore, the

386 reaction of a male to an intruder could also influence the mate choice of observing 
387 females (Otter et al. 1999; Mennill et al. 2002). Therefore, this is possibly a situation in

388 which the subjects always react persistently with full strength, without loosing time for

389 assessing the repertoire size broadcast. In such situations, birds may rather rely on quality

390 signals which can be immediately evaluated. In other territory intrusion experiments with

391 blackbirds, males responded more strongly to song playback with longer twitter part

392 duration (Dabelsteen \& Pedersen 1990), and in a different experiment, they reacted more

393 strongly to a model bird with yellow or orange beak than to models with brown beaks,

394 which are typical for yearling males (Bright \& Waas 2002). Unlike repertoire size, both

395 twitter part duration and beak colour can immediately be assessed.

396 We also considered a playback design using two speakers simultaneously, so that

397 the test bird would have to decide between the stimuli even though both impose a strong

398 threat, as used by Leitão \& Riebel (2003) or de Kort et al. (2009). However, the

399 assessment of large repertoires seems to be a rather complex task requiring to listen for

400 some time. In our experiments, the differences in repertoire sizes were not detectable

401 before listening to at least 20 songs and we wanted to avoid that in a two speaker design,

402 the test birds would decide for one speaker earlier during playback. In the mentioned

403 studies song traits were compared which can be immediately assessed (Leitão \& Riebel

404 2003: songs with vs. without the 'terminal flourish'; de Kort et al. 2009: consistency of

405 trill notes within one song).

406 Our negative result does of course not rule out the possibility that males evaluate

407 repertoire size in other situations. For example, a territory owner might listen to

408 neighbours singing outside the territory and use their repertoire sizes for quality 
assessment, which could influence decisions about future interactions like investment in

410 territorial fights or in mate guarding.

411 The large inter-individual differences in the test birds' repertoire sizes found in

412 this and previous studies (Rasmussen \& Dabelsteen 2002) and our findings in another

413 study, that larger males have larger repertoire sizes (Hesler 2010), imply that repertoire

414 size could serve as a quality signal in blackbirds. It is possible that repertoire size is

415 linked to male quality as in several other species (e.g. Hiebert et al. 1989; Mountjoy \&

416 Lemon 1996; Buchanan et al. 1999; Balsby 2000; Kipper et al. 2006) and used for quality

417 assessment, but only in inter-sexual contexts. This idea complements findings that sedge

418 warbler females react differently to playback of different repertoire sizes while males do

419 not (Catchpole 1989), and that in an experiment with starlings Sturnus vulgaris, territorial

420 males sang with a larger repertoire in the presence of a female than in the presence of a

421 male (Eens et al. 1993). Catchpole (1989) suggested that in the sedge warbler inter-sexual

422 selection has resulted in more complex songs and intra-sexual selection in simpler and

423 shorter songs. However, if females are able to use song characteristics for male quality

424 assessment, it would seem advantageous for males to do so as well. That repertoires in

425 general do not play a role in intra-sexual contexts in blackbirds seems unlikely, as they

426 also have a distinct singing style, the 'aggressive twitter' (Dabelsteen et al. 1998), which

427 is used exclusively in intra-sexual contexts during close range aggressive interactions

428 with males and has an even larger repertoire than normal full song (Klump et al. 2010).

429 It is also possible that not only repertoire size per se is the selected song trait, but

430 also how it is used and organised: even birds with same element repertoire sizes could

431 differ in sequential organisation or frequency distribution of their elements, or their 
432 ability of repertoire matching (Beecher et al. 2000). It could also be that special element

433 types, which are energetically demanding to produce, are the selected trait. In canaries

434 Serinus canaria it has been found that females prefer 'sexy syllables' which are

435 energetically demanding to produce (Vallet \& Kreutzer 1995; Leitner et al. 2006). Other

436 performance dependent song traits have been identified, which were linked to male

437 quality and/or preferred by females, as syllable type or trill consistency (tropical

438 mockingbird Mimus gilvus, Botero et al. 2009; banded wren Thryothorus pleurostictus,

439 de Kort et al. 2009) and the performance of rapid, broadband trills (swamp sparrow

440 Melospiza georgiana, Ballentine 2009), or song traits which depend on conditions during

441 early development, as syntax accuracy (zebra finch Taeniopygia guttata, Brumm et al.

442 2009; Holveck et al. 2008). In our design, we created both large and small playback files

443 from the same recording, which was always from an originally large repertoire bird, since

444 we could not enlarge repertoire sizes, but only reduce them. We did this in order to avoid

445 the influence of other song parameters correlated with repertoire size. However, this also

446 means that song traits other than repertoire size were present (or absent) in both test files.

447 If these effects were clearly stronger than repertoire size, responses towards different

448 stimulus birds would have differed, which was not the case. However, if both repertoire

449 size and other intrinsic song traits have an effect at the same time, an indifferent response

450 could result. An experimental design using both large and small repertoire from the same

451 stimulus bird for the same test bird would avoid this problem. On the other hand, in the

452 second experiment the test bird may then recognise the identity of the stimulus bird

453 (Weary \& Krebs 1992) from the first experiment and base its response partly on that.

454 Therefore we decided to use stimuli from different individuals for one test bird. 
Possibly the two distinct parts of the blackbird's song, the whistle and the twitter,

456 have different functions, as they also have different acoustic properties (the whistle part

457 has a much further transmission range than the twitter part and is more omni-directional,

458 Larsen \& Dabelsteen 1990; Dabelsteen et al. 1993). This means that they reach different

459 parts of the habitat. By using the habitat in different ways, female and male receivers may

460 thus not be equally exposed to the whistle and twitter part (Dabelsteen \& Pedersen 1988)

461 so that inter- and intra-sexual selection may act differently on these parts. This could be

462 tested by manipulating only one of the two song parts in a playback experiment (Leitão \&

463 Riebel 2003).

464 In conclusion, we found no evidence for the hypothesis, that male blackbirds use

465 repertoire sizes to assess a rival's fighting ability. However, the interpretation of negative

466 results is difficult. Possibly a ceiling effect lead to indifferent responses to the different

467 repertoire sizes. Also, it is possible that males use repertoire sizes for quality assessment

468 in other contexts than territory intrusion, such as listening to song outside their territory.

470 Acknowledgements

471 We thank T. Sacher, T. Coppack and F. Bairlein for collaboration and O. Hüppop with

472 the team of the Vogelwarte Helgoland and C. Horn for assistance during the field work.

473 We also thank I. Teschke for language improvement and two anonymous reviewers for

474 their helpful comments. The study was funded by a combined PhD fellowship from

475 NaFöG (Promotionsstipendium nach dem Nachwuchsförderungsgesetz des Landes

476 Berlin, Germany), SNAK (Graduate School on Sense organs, Nerve systems, Behaviour

477 and Communication, funded by the Danish Research Agency) and the University of 
478 Copenhagen to NH and a framework grant from the Danish Research Council for Nature

479 and Universe (no.272-07-0477) to TD. This study meets the guidelines for the treatment

480 of animals in behavioural research and teaching of the Association for the Study of

481 Animal Behaviour and complies with laws in Germany and Denmark.

483 References

484 Aiken, L S \& West, S G 1992 Multiple Regression: Testing and Interpreting Interactions 485 Newbury Park, Sage.

486 Baayen, R H 2008a languageR: Data sets and functions with "Analyzing Linguistic Data: $487 \quad$ A practical introduction to statistics".

488 Baayen, R H 2008b Analyzing Linguistic Data: A practical introduction to statistics using 489 R. University Press, Cambridge.

490 Ballentine, B (2009) The ability to perform physically challenging songs predicts age and 491 size in male swamp sparrows, Melospiza georgiana. Anim Behav 77, 973-978.

492 Balsby, T J S (2000) The function of song in whitethroats Sylvia communis. Bioacoustics $493 \quad 11,17-30$.

494 Balsby, T J S and Dabelsteen, T (2001) The meaning of song repertoire size and song 495 length to male whitethroats Sylvia communis. Behavioural Processes 56, 75-84.

496 Bates, D, Maechler, M and Dai, B (2008) lme4: Linear mixed-effects models using S4 classes.

498 Beecher, M D Campbell, S E, and Nordby, J C (2000) Territory tenure in song sparrows 499 is related to song sharing with neighbours, but not to repertoire size. Anim Behav $500 \quad 59,29-37$. 
501 Bolker, B M, Brooks, ME Clark, C J, Geange, S W, Poulsen, J R, Stevens, M H, and

502 White, J S (2009) Generalized linear mixed models: a practical guide for ecology

503 and evolution. Trends in Ecology \& Evolution 24, 127-135.

504 Botero, C A, Rossman, R J, Caro, L M, Stenzler, L M, Lovette, I J, de Kort, S R, and

$505 \quad$ Vehrencamp, S L (2009) Syllable type consistency is related to age, social status

506 and reproductive success in the tropical mockingbird. Anim Behav 77, 701-706.

507 Briefer, E, Aubin, T, Lehongre, K, and Rybak, F (2008) How to identify dear enemies:

508 the group signature in the complex song of the skylark Alauda arvensis. Journal

$509 \quad$ of Experimental Biology 211, 317-326.

510 Bright, A and Waas, J R (2002) Effects of bill pigmentation and UV reflectance during

511 territory establishment in blackbirds. Anim Behav 64, 207-213.

512 Brumm, H, Zollinger, S A, and Slater, P J B (2009) Developmental stress affects song

513 learning but not song complexity and vocal amplitude in zebra finches. Behav

$514 \quad$ Ecol Sociobiol 63, 1387-1395.

515 Buchanan, K L, Catchpole, C K, Lewis, J W, and Lodge, A (1999) Song as an indicator

516 of parasitism in the sedge warbler. Anim Behav 57, 307-314.

517 Catchpole, C K (1980) Sexual selection and the evolution of complex songs among

518 European warblers of the genus Acrocephalus. Behaviour 74, 149-165.

519 Catchpole, C K (1989) Responses of male sedge warblers to playback of different

$520 \quad$ repertoire sizes. Anim Behav 37, 1046-1047.

521 Catchpole, C K and Slater, P J B 2008 Bird song - biological themes and variations, 2

522 edn: Cambridge University Press. 
523 Collins, S A (2004) Vocal fighting and flirting: the functions of birdsong. In Marler P,

524 and Slabbekoorn H (eds) Nature's Music, Elsevier Academic Press, London, pp.

$525 \quad 39-79$.

526 Dabelsteen, T (1981) The Sound Pressure Level in the Dawn Song of the Blackbird

527 Turdus merula and a Method for Adjusting the Level in Experimental Song to the

$528 \quad$ Level in Natural Song. Z Tierpsychol 56, 137-149.

529 Dabelsteen, T (1982) Variation in the Response of Freeliving Blackbirds Turdus merula

530 to Playback of Song: I.Effect of Continuous Stimulation and Predictability of the

$531 \quad$ Response. Z Tierpsychol 58, 311-328.

532 Dabelsteen, T (1984) An analysis of the full song of the Blackbird Turdus merula with

533 respect to message coding and adaptations for acoustic communication. Ornis

$534 \quad$ Scandinavica $15,227-239$.

535 Dabelsteen, T and Pedersen, S B (1985) Correspondence between Messages in the Full

$536 \quad$ Song of the Blackbird Turdus merula and Meanings to Territorial Males, as

537 Inferred from Responses to Computerized Modifications of Natural Song. Z

$538 \quad$ Tierpsychol 69, 149-165.

539 Dabelsteen, T and Pedersen, S B (1988) Do Female Blackbirds, Turdus merula, Decode

$540 \quad$ Song in the Same Way as Males? Anim Behav 36, 1858-1859.

541 Dabelsteen, T and Pedersen, S B (1990) Song and information about aggressive

542 responses of blackbirds, Turdus merula: evidence from interactive playback

543 experiments with territory owners. Anim Behav 40, 1158-1168.

544 Dabelsteen, T, Larsen, O N, and Pedersen, S B (1993) Habitat-induced degradation of

545 sound signals: Quantifying the effects of communication sounds and bird location 
on blur ratio, excess attenuation, and signal-to-noise ratio in blackbird song.

547 Journal of the Acoustic Society of America 93, 2206-2220.

548 Dabelsteen, T, McGregor, P K, Lampe, H M, Langmore, N E, and Holland, J (1998)

549 Quiet song in song birds: an overlooked phenomenon. Bioacoustics 9, 89-105.

550 Dabelsteen, $\mathrm{T}$ (2005) Public, private or anonymous? Facilitating and countering

551 eavesdropping. In McGregor P K (ed) Animal Communication Networks,

552 Cambridge University Press, Cambridge, pp. 38-62.

553 de Kort, S R, Eldermire, E R B, Valderrama, S, Botero, C A, and Vehrencamp, S L 2009

554 Trill consistency is an age-related assessment signal in banded wrens. Proc Roy

$555 \quad$ Soc London Ser B 276, 2315-2321.

556 Dobson, A J (2002) An introduction to generalized linear models. Chapman \& Hall/CRC, $557 \quad$ Boca Raton,FL.

558 Eens, M, Pinxten, R, and Verheyen, R F (1993) Function of the Song and Song

$559 \quad$ Repertoire in the European Starling (Sturnus vulgaris) - An Aviary Experiment.

$560 \quad$ Behaviour 125, 51-66.

561 Field, A (2005) Discovering statistics using SPSS. Sage Publications, London.

562 Gentner, T Q, Hulse, S H, Bentley, G E, and Ball, G F (2000) Individual vocal

563 recognition and the effect of partial lesions to HVc on discrimination, learning,

564 and categorization of conspecific song in adult songbirds. J Neurobiol 42, 117-

565133.

566 Hesler N (2010) Song complexity in common blackbirds - an honest signal of male

567 quality? Dissertation, University of Copenhagen. 
568 Hiebert, S M, Stoddard, P K, and Arcese, P (1989) Repertoire size, territory acquisition and reproductive success in the song sparrow. Anim Behav 37, 266-273.

570 Holveck, M J, de Castro, A C V, Lachlan, R F, Ten Cate, C, and Riebel, K (2008)

571 Accuracy of song syntax learning and singing consistency signal early condition 572 in zebra finches. Behav Ecol 19, 1267-1281.

573 Kipper, S, Mundry, R, Hultsch, H, and Todt, D (2004) Long-term persistence of song 574 performance rules in nightingales (Luscinia megarhynchos): a longitudinal field $575 \quad$ study on repertoire size and composition. Behaviour 141, 371-390.

576 Kipper, S, Mundry, R, Sommer, C, Hultsch, H, and Todt, D (2006) Song repertoire size is 577 correlated with body measures and arrival date in common nightingales, Luscinia 578 megarhynchos. Anim Behav 71, 211-217.

579 Klump, B, Hesler, N, and Dabelsteen, T (2010) Quiet song in common blackbirds 580 repertoire size and use in an aggressive context. Conference abstract, Bioacoustics $581 \quad$ in press.

582 Krebs, J, Ashcroft, R, and Webber, M (1978) Song repertoires and territory defence in 583 the great tit. Nature 271, 539-542.

584 Larsen, O N and Dabelsteen, T (1990) Directionality of Blackbird vocalization.

585 Implications for vocal communication and its further study. Ornis Scandinavica $586 \quad 21,37-45$.

587 Leitão, A and Riebel, K 2003 Are good ornaments bad armaments? Male chaffinch 588 perception of songs with varying flourish length. Anim Behav 66, 161-167.

589 Leitão, A, Ten Cate, C, and Riebel, K 2006 Within-song complexity in a songbird is 590 meaningful to both male and female receivers. Anim Behav 71, 1289-1296. 
591 Leitner, S, Marshall, R C, Leisler, B, and Catchpole, C K (2006) Male song quality, egg

592 size and offspring sex in captive canaries ( Serinus canaria). Ethology 112, 554-

593563.

594 McGregor, P K (1992) Quantifying responses to playback: one, many, or composite

595 multivariate measures? In McGregor P K (ed) Playback and Studies of Animal

596 Communication, Plenum Press, New York and London, 79-96.

597 Mennill, D J, Ratcliffe, L M, and Boag, P T (2002) Female Eavesdropping on Male Song

$598 \quad$ Contests in Songbirds. Science 296, 873.

599 Mountjoy, D J and Lemon, R E (1996) Female choice for complex song in the European

600 starling: a field experiment. Behav Ecol Sociobiol 38, 65-71.

601 Otter, K, McGregor, P K, Terry, A M R, Burford, F R L, Peake, T M, and Dabelsteen, T

602 (1999) Do female great tits (Parus major) assess males by eavesdropping? A field

603 study using interactive song playback. Proc Roy Soc London Ser B 266, 1305-

$604 \quad 1309$.

605 R Development Core Team. (2008) R: A language and environment for statistical

606 computing. R Foundation for Statistical Computing. Vienna, Austria.

607 Rasmussen, R and Dabelsteen, T (2002) Song repertoires and repertoire sharing in a local

608 group of Blackbirds. Bioacoustics 13, 63-76.

609 Sacher, T, Engler, J, Gorschewski, A, Gottschling, M, Hesler, N, Bairlein, F, and

610 Coppack, T (2006) Die Helgoländer Amselpopulation: ein Modell für

611 Populationsgenetik und Zugbiologie. Ornithologischer Jahresbericht Helgoland

$612 \quad 16,76-84$. 
613 Searcy, W A (1983) Response to multiple song types in male song sparrows and field 614 sparrows. Anim Behav 31, 948-949.

615 Searcy, W A and Beecher M D (2009) Song as an aggressive signal in songbirds. Anim $616 \quad$ Behav 78, 1281-1292.

617 Stoddard, P K, Beecher, M D, and Willis, M S (1988) Response of territorial male song 618 sparrows to song types and variations. Behav Ecol Sociobiol 22, 125-130.

619 Svensson, L (1992) Identification Guide to European Passerines. Svensson, Stockholm.

620 Todt, D (1981) On Functions of Vocal Matching: Effect of Counter-replies on Song Post $621 \quad$ Choice and Singing. Z Tierpsychol 57, 73-93.

622 Vallet, E and Kreutzer, M (1995) Female Canaries Are Sexually Responsive to Special 623 Song Phrases. Anim Behav 49, 1603-1610.

624 Weary, D M and Krebs, J R (1992) Great tits classify songs by individual voice $625 \quad$ characteristics. Anim Behav 43, 283-287.

626 Yasukawa, K (1981) Song repertoires in the red-winged blackbird (Agelaius phoeniceus):

627 A test of the Beau Geste hypothesis. Anim Behav 29, 114-125.

628

629 
631 Table 1 Results of the PCA for data obtained during and after playback. The Kaiser-

632 Meyer-Olkin measure of sampling adequacy (K-M-O) and Bartlett's test of sphericity

633 (Bartlett's $\chi^{2}$, df and P) justified both PCAs. Response variables which contributed most

634 to the respective components (PC1, PC2, PC3) are in bold. After playback the behaviours

635 bow, flight and tail up occurred too rarely to include them in the analysis. Transf.:

636 Variables were transformed to achieve normality or uniformity if needed according to

637 visual inspection; log: log transformed, sqrt: square root transformed.

\begin{tabular}{|c|c|c|c|c|c|c|c|}
\hline & \multicolumn{4}{|c|}{ during playback } & \multicolumn{3}{|c|}{ after playback } \\
\hline K-M-O & \multicolumn{4}{|c|}{0.58} & \multicolumn{3}{|c|}{0.49} \\
\hline Bartlett's $\chi^{2}$ & \multicolumn{4}{|c|}{114.2} & \multicolumn{3}{|c|}{48.6} \\
\hline Bartlett's df & \multicolumn{4}{|c|}{30} & \multirow{2}{*}{\multicolumn{3}{|c|}{6}} \\
\hline Bartlett's P & \multicolumn{4}{|c|}{$<0.001$} & \multicolumn{2}{|c|}{$<0.001$} & \\
\hline variable & transf. & PC1 & PC2 & PC3 & transf. & PC1 & PC2 \\
\hline mean distance $[\mathrm{m}]$ & - & 0.94 & 0.07 & 0.08 & - & 0.96 & 0.12 \\
\hline rate of bow $[1 / \mathrm{sec}]$ & sqrt & -0.82 & 0.04 & 0.10 & - & - & - \\
\hline minimum distance $[\mathrm{m}]$ & - & $\mathbf{0 . 8 0}$ & -0.36 & 0.05 & - & 0.96 & -0.09 \\
\hline rate of flight $[1 / \mathrm{sec}]$ & - & -0.06 & 0.84 & 0.08 & sqrt & -0.10 & 0.89 \\
\hline rate of tail up $[1 / \mathrm{sec}]$ & - & -0.18 & 0.75 & -0.19 & sqrt & 0.13 & 0.88 \\
\hline latency flight [sec] & $\log$ & -0.05 & -0.68 & 0.55 & - & - & - \\
\hline mean timing tail up [sec] & - & -0.05 & 0.37 & 0.78 & - & - & - \\
\hline mean timing flight [sec] & - & 0.25 & -0.31 & 0.76 & - & - & - \\
\hline latency tail up [sec] & $\log$ & -0.12 & -0.23 & 0.69 & - & - & - \\
\hline Eigenvalue & & 2.95 & 2.10 & 1.44 & & 1.88 & 1.59 \\
\hline$\%$ variance explained & & 32.76 & 23.37 & 15.98 & & 47.02 & 39.69 \\
\hline
\end{tabular}

639 Table 2 GLMM results of the playback experiments. Given are P-values (MCMC) and

$64095 \%$ confidence interval limits (lower CI, upper CI) of final models without considering

641 the subjects' own repertoire sizes (one fitted for each response variable). The predictor

642 variable, repertoire size of playback stimulus, did not have a significant effect on any of

643 the response variables. Test: response variables obtained during playback; after: response

644 variables obtained in the $120 \mathrm{sec}$ after playback. N: sample size. Indicated P-values are

645 without correction for multiple testing. For details of the PC factors see Table 1. 


\begin{tabular}{llrrrr}
\hline \multicolumn{1}{c}{ Response variable } & \multicolumn{1}{c}{ Predictor variable } & lower CI & upper CI & p MCMC & N \\
\hline test distance slope & repertoire size of stimulus & -0.321 & 0.473 & $\mathbf{0 . 7 3 3}$ & 32 \\
test PC 1 & repertoire size of stimulus & -0.479 & 0.234 & $\mathbf{0 . 5 5 2}$ & 32 \\
test PC 2 & repertoire size of stimulus & -0.311 & 0.379 & $\mathbf{0 . 8 4 0}$ & 32 \\
test PC 3 & repertoire size of stimulus & -0.515 & 0.203 & $\mathbf{0 . 3 7 1}$ & 32 \\
after distance slope & repertoire size of stimulus & -0.836 & 0.936 & $\mathbf{0 . 9 0 6}$ & 29 \\
after PC 1 & repertoire size of stimulus & -0.491 & 0.248 & $\mathbf{0 . 4 7 1}$ & 29 \\
after PC 2 & repertoire size of stimulus & -0.575 & 0.206 & $\mathbf{0 . 3 8 2}$ & 29 \\
\hline
\end{tabular}

647 Table 3 GLMM results of the playback experiments. Given are P-values (MCMC) and

$64895 \%$ confidence interval limits (lower CI, upper CI) from final models including the

649 subjects' own repertoire sizes (one fitted for each response variable). None of the

650 predictor variables had a significant influence on any of the response variables.

651 Test/after: response variables obtained during/in the $120 \mathrm{sec}$ after the experiment. N:

652 sample size. For details of the PCs see Table 1. Since after PC 2 was involved in a

653 marginally non-significant interaction, the values for the involved variables repertoire

654 size of stimulus and repertoire size of test subject are not indicated. Indicated P-values are

655 without correction for multiple testing.

\begin{tabular}{llrrrr}
\hline \multicolumn{1}{c}{ Response variable } & \multicolumn{1}{c}{ Predictor variable } & lower CI & upper CI & p MCMC & N \\
\hline test distance slope & repertoire size of stimulus & -0.457 & 0.320 & $\mathbf{0 . 7 3 4}$ & 30 \\
test distance slope & repertoire size of test subject & -0.628 & 0.159 & $\mathbf{0 . 2 3 1}$ & 30 \\
test PC 1 & repertoire size of stimulus & -0.479 & 0.280 & $\mathbf{0 . 5 7 7}$ & 30 \\
test PC 1 & repertoire size of test subject & -0.487 & 0.315 & $\mathbf{0 . 6 5 9}$ & 30 \\
test PC 2 & repertoire size of stimulus & -0.414 & 0.306 & $\mathbf{0 . 7 9 8}$ & 30 \\
test PC 2 & repertoire size of test subject & -0.590 & 0.188 & $\mathbf{0 . 2 9 7}$ & 30 \\
test PC 3 & repertoire size of stimulus & -0.421 & 0.289 & $\mathbf{0 . 7 5 2}$ & 30 \\
test PC 3 & repertoire size of test subject & -0.085 & 0.642 & $\mathbf{0 . 1 4 0}$ & 30 \\
after distance slope & repertoire size of stimulus & -0.769 & 0.999 & $\mathbf{0 . 6 9 7}$ & 27 \\
after distance slope & repertoire size of test subject & -0.230 & 1.585 & $\mathbf{0 . 1 5 1}$ & 27 \\
after PC 1 & repertoire size of stimulus & -0.443 & 0.318 & $\mathbf{0 . 7 3 8}$ & 27 \\
after PC 1 & repertoire size of test subject & -0.708 & 0.102 & $\mathbf{0 . 1 4 6}$ & 27 \\
& interaction between repertoire size & & & & \\
after PC 2 & of stimulus and test subject & -0.906 & 0.049 & $\mathbf{0 . 0 8 0}$ & 27 \\
\hline
\end{tabular}




\title{
658 Figure captions
}

659 Fig. 1 Spectrograms of four consecutive blackbird songs with indication of

660 whistle/twitter parts and single elements. Numbers indicate different element types. Note

661 that some of the element types of song 1a) occur also in the song 1c) and d).

662

663 Fig. 2 Element repertoire sizes of test subjects. The number of different element types is

664 depicted against the number of analysed songs.
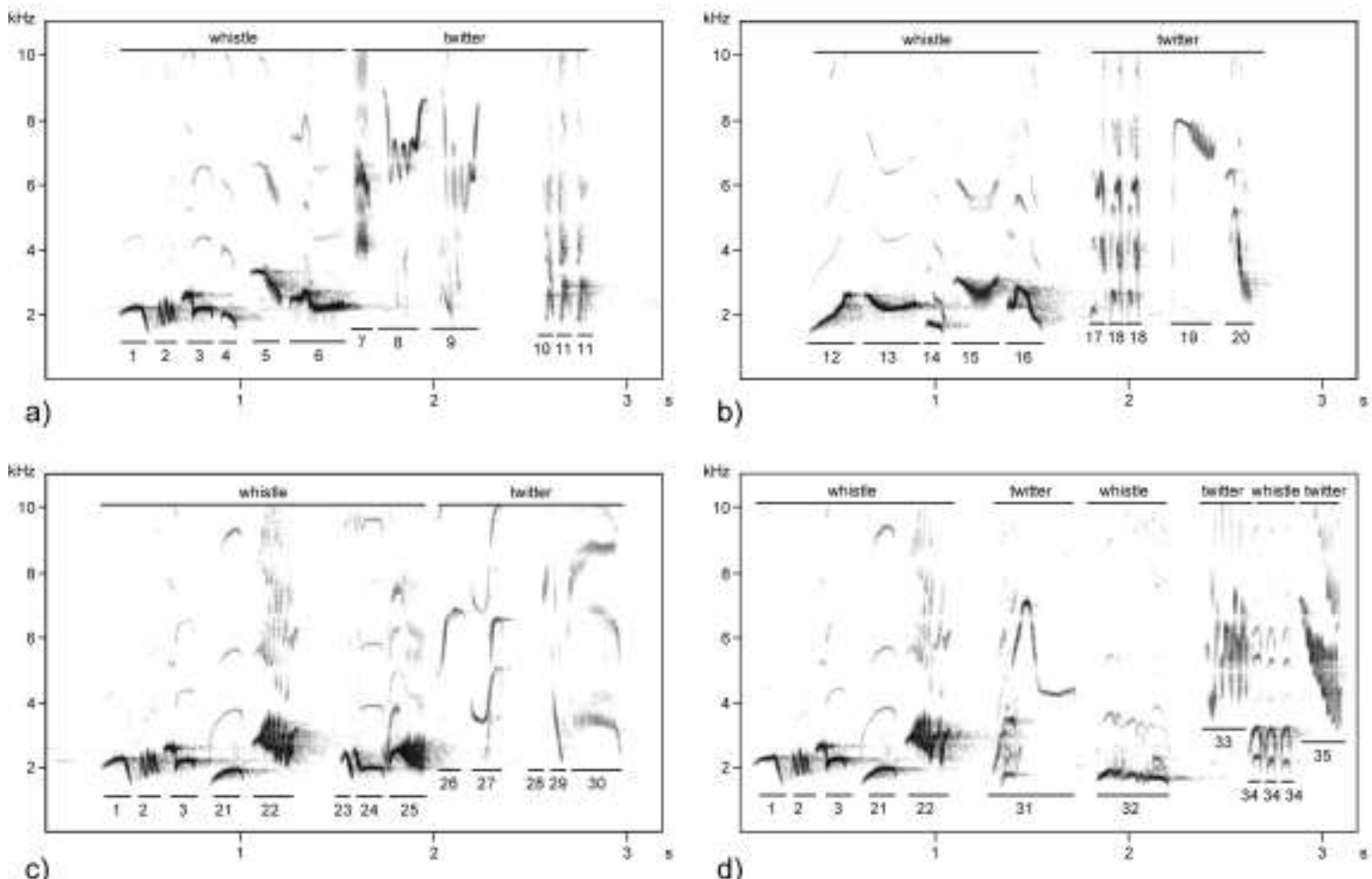

665

\begin{abstract}
c)
\end{abstract}
d) 
666

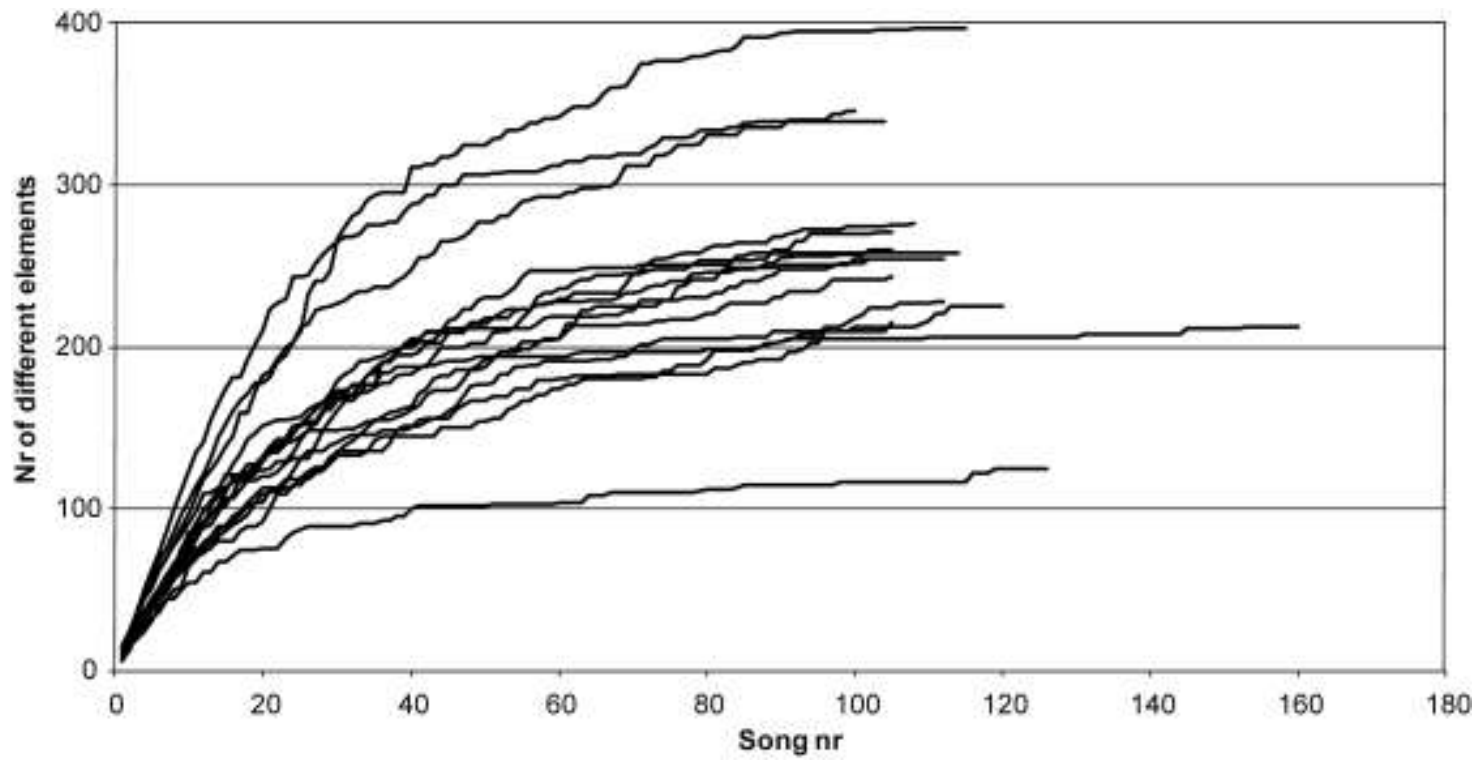

